\title{
Francisella noatunensis subsp. noatunensis is the aetiological agent of visceral granulomatosis in wild Atlantic cod Gadus morhua
}

\author{
Mulualem Adam Zerihun ${ }^{1, *}$, Stephen W. Feist ${ }^{2}$, David Bucke ${ }^{3}$, A. B. Olsen ${ }^{4}$, \\ Nora M. Tandstad ${ }^{1}$, Duncan J. Colquhoun ${ }^{1}$ \\ ${ }^{1}$ The Norwegian Veterinary Institute, Ullevaalsveien 68, 0106 Oslo, Norway \\ ${ }^{2}$ Centre for Environment, Fisheries and Aquaculture Science, Barrack Road, The Nothe, Weymouth, Dorset DT4 8UB, UK \\ ${ }^{3} 3$ b Roundhayes Close, Weymouth, Dorset DT4 0RN, UK \\ ${ }^{4}$ The National Veterinary Institute, PB 1263, 5003 Bergen, Norway
}

\begin{abstract}
During the 1980s and 1990s wild-caught cod displaying visceral granulomatosis were sporadically identified from the southern North Sea. Presumptive diagnoses at the time included mycobacterial infection, although mycobacteria were never cultivated or observed histologically from these fish. Farmed cod in Norway displaying gross pathology similar to that identified previously in cod from the southern North Sea were recently discovered to be infected with the bacterium Francisella noatunensis subsp. noatunensis. Archived formalin-fixed paraffin-embedded tissues from the original North Sea cases were investigated for the presence of Mycobacterium spp. and Francisella spp. using real-time polymerase chain reaction, DNA sequencing and immunohistochemistry. Whilst no evidence of mycobacterial infection was found, F. noatunensis subsp. noatunensis was identified in association with pathological changes consistent with Francisella infections described from farmed cod in recent years. This study shows that francisellosis occurred in wild-caught cod in the southern North Sea in the 1980s and 1990s and demonstrates that this disease predates intensive aquaculture of cod.
\end{abstract}

KEY WORDS: Francisellosis · Francisella noatunensis · Mycobacterium · Granulomatosis · Mycobacteriosis · Atlantic cod · Immunohistochemistry · Real-time PCR · Formalin-fixed paraffinembedded tissue

\section{INTRODUCTION}

During a 5 yr surveillance study of disease prevalence in wild cod in the southeastern area of the North Sea between 1981 and 1985, a condition macroscopically described as 'presumptive mycobacteriosis' was identified annually with prevalence of up to $12.5 \%$ (Van Banning 1987). During the summer of 1988, the condition now referred to as 'visceral granulomatosis' was again identified. These reports related to Atlantic cod Gadus morhua caught around the southeast coast of England, including the outer Thames estuary and southern North Sea, although individual cases were reported from as far west as Dorset (MAFF 1991). Only cod were affected and lesions were observed in $8 \%$ of fish examined. However, reports from commercial fishermen and anglers suggested that the prevalence may have been as high as $30 \%$ (Bucke 1989). Macroscopically visible abnormalities included multi-organ (usually liver, spleen, kidney and heart) discoloration and the presence of pale nodules and cystic structures. Fish suffering from visceral granulomatosis were reported by fish processors, commercial fishermen and recreational anglers. Attempts to culture bacteria on selec- 
tive media (Dorset egg agar, Lowenstein's medium and seawater agar) and histopathological investigations carried out at that time did not reveal the aetiology of the disease. The disease was also been reported sporadically in later years (MAFF 1991, Cefas 2003).

Francisella spp. are bacterial pathogens of farmed and wild fish and shellfish species (Birkbeck et al. 2011). F. noatunensis subsp. noatunensis infections in farmed and wild Atlantic cod in southwest Norway and on the Swedish west coast (Olsen et al. 2006, Alfjorden et al. 2006) have been found to induce chronic granulomatous pathological changes in the kidney, spleen, liver and heart of infected fish similar to those observed in visceral granulomatosis/presumptive mycobacteriosis. The aetiological agent of francisellosis in cod, F. noatunensis subsp. noatunensis $(=F$. piscicida) (Mikalsen et al. 2007, Ottem et al. 2007, 2009), does not grow on the culture media previously used in the visceral granulomatosis/presumptive mycobacteriosis investigations. Histopathologically, similarities exist between visceral granulomatosis/presumptive mycobacteriosis and francisellosis.

The present retrospective study, based on analysis of formalin-fixed paraffin-embedded (FFPE) tissues archived from 1988, was therefore performed in an effort to establish the possible aetiological roles of Francisella and mycobacteria in the condition described as visceral granulomatosis/presumptive mycobacteriosis in the southern North Sea.

\section{MATERIALS AND METHODS}

Tissue samples. FFPE tissue blocks of heart, spleen and liver from 13 Atlantic cod sampled from the southern North Sea during October and November 1988 were retrieved from the Centre for Environment, Fisheries and Aquaculture Science (Cefas) archive collection of histological material. These samples were representative of the gross pathological changes typical of visceral granulomatosis/presumptive mycobacteriosis which were present in 61 out of 749 examined fish. Atlantic cod tissues, positive for Francisella noatunensis subsp. noatunensis and Mycobacterium spp. were taken from clinical cases (including the original case from which F. noatunensis NCIMB 14265, the strain used in the present study, was isolated) submitted to the Norwegian Veterinary Institute (NVI) and from experimental infections, respectively.

Histopathology. Sections $(5 \mu \mathrm{m})$ were taken from the FFPE blocks and stained with hematoxylin and eosin (H\&E). Parallel sections were stained with Gram and Ziehl-Neelsen (ZN) stains for visualization of bacterial presence and immunostained using antisera produced against $F$. noatunensis subsp. noa- tunensis and mycobacteria as described below. All sections were examined for the presence of bacteria, granuloma, inflammatory foci, or necrotic lesions characteristic of francisellosis and/or mycobacterial infections.

Polyvalent anti-Francisella noatunensis subsp. noatunensis rabbit serum production. $F$. noatunensis subsp. noatunensis (NCIMB 14265) was cultivated on cysteine agar at $22^{\circ} \mathrm{C}$ for $4 \mathrm{~d}$ and bacteria were harvested by scraping, washed twice and suspended in phosphate-buffered saline (PBS). Formalin was added to the bacterial suspension at a final concentration of $0.7 \%$ and after storage overnight at $4^{\circ} \mathrm{C}$ an aliquot was streaked onto cysteine heart agar (Olsen et al. 2006) to confirm inactivation. The bacterial cell suspension was washed twice with PBS and cell suspension adjusted to a density of $1 \times 10^{9} \mathrm{cells} \mathrm{ml}^{-1}$. The bacterial suspension was emulsified with an equal volume of Freund's incomplete adjuvant. A chinchilla rabbit (K43) was inoculated subcutaneously at multiple sites with a bacterial suspension. Initial inoculations were given twice weekly in consecutive doses of $0.2,0.4,0.8$ and $1.0 \mathrm{ml}$. Secondary inoculation $(1.0 \mathrm{ml})$ was administered $2 \mathrm{wk}$ after the last primary inoculation. Seven days after the secondary immunization, the rabbit was exsanguinated and the blood allowed to clot for $6 \mathrm{~h}$ at room temperature.

The serum was harvested and cross-adsorbed: aliquots of $1.5 \mathrm{ml}$ were placed into microcentrifuge tubes containing a pellet $(50$ to $60 \mu \mathrm{l})$ of washed Mycobacterium sp. NVI6598 cells and incubated at $37^{\circ} \mathrm{C}$ for $1 \mathrm{~h}$ and then overnight in a chilled room. Following centrifugation $(10000 \times g$ for $10 \mathrm{~min})$ the supernatant was stored at $-20^{\circ} \mathrm{C}$ until use.

Immunohistochemistry. The immunohistochemistry (IHC) procedure used was essentially as described by Thoresen et al. (1994) with slight modifications. Briefly, $3 \mu \mathrm{m}$ tissue sections were cut with a microtome (Leica Jung RM 2055) and mounted on poly-L-lysine coated slides. The slides were incubated at $65^{\circ} \mathrm{C}$ for $25 \mathrm{~min}$. Deparaffinization and rehydration of tissue sections was performed in a series of xylene, graded ethanol and water baths. Tissue sections were rehydrated in citrate buffer (0.1 M citric acid, $\mathrm{pH}$ 6.0) and boiled for $2 \times 6 \mathrm{~min}$ in a microwave oven $(800 \mathrm{~W})$ and after each heating left for 5 and $15 \mathrm{~min}$, respectively, in the warm solution. Slides were washed with Tris-buffered saline (TBS; $50 \mathrm{mM}$ Tris- $\mathrm{HCl}, 150 \mathrm{mM} \mathrm{NaCl}, \mathrm{pH}$ 7.6) with $0.05 \%(\mathrm{v} / \mathrm{v})$ Tween 20, and incubated for 20 min with a blocking solution $(5 \%[\mathrm{w} / \mathrm{v}]$ bovine serum albumin [BSA] in PBS). Sections were incubated for $1 \mathrm{~h}$ with a 1:30 000 dilution of rabbit anti-Francisella noatunensis subsp. noatunensis serum, washed in TBS containing Tween 20, incubated for 30 min with secondary antibody (Biotinylated goat anti-rabbit IgG; GE Health) 
diluted 1:500 in 2.5\% BSA, washed in TBS with Tween 20 , and incubated for 30 min with a 1:500 dilution of streptavidin-biotin alkaline phosphatase (GE Health). Following a final wash, Fast Red (1 $\left.\mathrm{mg} \mathrm{ml}^{-1}\right)$ and Naphtol AS-MX phosphate $\left(0.2 \mathrm{mg} \mathrm{ml}^{-1}\right)$ with $1 \mathrm{mM}$ Levamisole in $0.1 \mathrm{M}$ TBS (pH 8.2) were added and allowed to develop for 20 min. Finally, sections were counterstained with hematoxylin and mounted with Aquatex (VWR International). All incubations were conducted in a humid chamber at room temperature.

Positive and negative control tissues were taken from Atlantic cod and included in testing tissues. Controls were also tested by excluding primary, secondary and both antibodies.

Testing specificity of the immunohistochemistry assay. The Francisella noatunensis immunohistochemistry assay was tested for specificity against a taxonomically broad array of disease causing agents in FFPE tissues, isolated from clinical cases submitted to the NVI (Table 1). With the exception of minor non-specific cross-reaction recorded in a few tissue sections infected with atypical Aeromonas salmonicida, all other tissues included for specificity testing were negative. The cross-reaction with atypical $A$. salmonicida was eliminated following cross-adsorption with 3 different surface antigen (vapA) variants of A. salmonicida.

The mycobacterium immunohistochemistry was performed as described by Zerihun et al. (2011). This tech- nique detects both fast and slow-growing fish-relevant mycobacterial species at the genus level, including Mycobacterium chelonae, M. salmoniphilum, M. fortuitum and $M$. marinum.

DNA extraction. DNA was extracted from FFPE tissues using the Nucleon Hard Tissue (HT) Kit (Amersham Biosciences) following the manufacturer's recommendations with slight modifications. In brief, 4 parallel $5 \mu \mathrm{m}$ thick tissue sections were cut with a microtome (Leica Jung RM 2055) and collected into one sterile $1.5 \mathrm{ml}$ Eppendorf tube for each paraffin block. A new microtome blade was used for each paraffin block and several initial sections were discarded from each block to avoid possible contaminations. One $\mathrm{ml}$ of xylene was then added to the tube containing the tissue sections, which was then vortexed vigorously and the supernatant was discarded after $5 \mathrm{~min}$ of centrifugation at $13000 \times g$ at room temperature. Xylene washing was repeated twice and followed by washing with $96 \%$ ethanol as above. After the last wash, open tubes were incubated at $37^{\circ} \mathrm{C}$ for 15 min for elimination of remaining ethanol.

Real-time PCR. The Fc50 (specific for Francisella noatunensis and F. asiatica) and FopA (specific for $F$. noatunensis and $F$. philomeragia) real-time PCR assays targeting the 16S rRNA gene and the outer membrane protein gene, respectively, were performed as described by Ottem et al. (2008), except that a $20 \mu \mathrm{l}$ PCR reaction was performed with TaqMan ${ }^{\circledR}$ Universal PCR

Table 1. Formalin-fixed paraffin-embedded tissue blocks included in specificity testing of the Francisella noatunensis subsp. noatunensis immunohistochemistry (IHC) assay. VER/VNN: viral encephalo- and retinopathy/viral nervous necrosis

\begin{tabular}{|llcl|}
\hline Case ID & Diagnosis & Host & Anti-F. noatunensis IHC \\
\hline $01-09893$ & Aeromonas salmonicida subsp. salmonicida & Atlantic salmon & - \\
$05-09366$ & Atypical A. salmonicida & Atlantic cod & - \\
$05-09250$ & Yersinia ruckeri & Atlantic salmon & - \\
$00-09288$ & Moritella viscosa & Atlantic salmon & - \\
$06-09025$ & Vibrio anguillarum & Atlantic cod & - \\
$02-09091$ & Vibrio salmonicida & Rainbow trout & - \\
$06-09699$ & Piscrickettsia salmonis & Atlantic salmon & - \\
$01-091173$ & Renibacterium salmoninarum & Atlantic salmon & - \\
446 & Rhodococcus erythropolis & Atlantic salmon & - \\
315 & Nocardia seriolae & Amberjack & - \\
$08-09072$ & Mycobacterium salmoniphilum & Atlantic cod & - \\
$08-09505$ & Mycobacterium marinum & Turbot & - \\
$04-09184$ & Viral hemorrhagic septicaemia & Rainbow trout & - \\
$07-09676$ & Infectious pancreatic necrosis & Atlantic salmon & - \\
$05-09645$ & VER/VNN & Atlantic halibut & - \\
$06-09080$ & Infectious salmon anaemia & Atlantic salmon & - \\
$08-08399$ & Parasitic granulomatosis & Burbot & - \\
$05-09181$ & Microsporidial infection & Atlantic cod & - \\
$04-09597$ & Coccidial infection & Atlantic cod & - \\
$03-09123$ & Fungal infection & Atlantic salmon & - \\
$06-09508$ & Francisella noatunensis subsp. noatunensis & Atlantic cod & \\
$06-09708$ & Healthy looking tissue & Atlantic cod & - \\
\hline
\end{tabular}


Master Mix (Applied Biosystems) which was run on an Mx3005P Instrument (Stratagene). Each real-time PCR run included both positive and negative (water) controls. All samples were similarly tested against mycobacterial infections using the genus-specific realtime PCR assay described by Zerihun et al. (2011).

Cloning and sequencing. Using $2 \mu \mathrm{l}$ of the Fc50 realtime PCR positive product as template, conventional PCR was run with primers FCF50 and FCR50 and Taq DNA polymerase with ThermoPol Buffer (New England Biolabs). Positive products from the conventional PCR product were cloned into $\mathrm{pCR}{ }^{\circledR} 4 \mathrm{TOPO}{ }^{\circledR}$ (Invitrogen) according to the manufacturer's protocol. Briefly, transformants were analyzed with PCR using the vector-specific primers M13F and M13R. PCR positive products were purified using Nucleospin ${ }^{\circledR}$ Extract II (Macherey-Nagel) and sequenced in both directions using the same primer set. The sequence reaction mixture comprised $2 \mu \mathrm{l}$ of purified PCR product, $4 \mu \mathrm{L}$ DYEnamic $^{\text {TM }}$ Dye Terminator Cycle Sequencing Kit (Amersham Biosciences), $1 \mu$ sequencing primer $(5 \mu \mathrm{M})$ and $3 \mu \mathrm{l}$ sterile distilled water. Sequencing products were purified using a DYE Terminator Removal Kit (ABgene ${ }^{\circledR}$ ) and separated on a MegaBACE 1000 sequencing instrument (Amersham Biosciences). Consensus sequences were determined using Vector NTI (Invitrogen) and the identity of the Fc50 real-time PCR product was confirmed using BLAST search analysis (Altschul et al. 1997).

\section{RESULTS}

\section{Histopathology}

Tissue sections prepared from all received samples and stained using $\mathrm{H} \& \mathrm{E}$ showed varying stages of granuloma. Most granuloma consisted of aggregates of elongated radially arranged cells (histocytes). In older lesions the cellular centres had degenerated into necrotic masses. Lesions presenting as cystic nodules (granulomas) were frequently observed during necropsy and appeared histologically as granulomatous lesions with central cavities containing few or no cells (Fig. 1E). All samples were ZN-negative and no bacteria were detectable in Gram- or H\&E-stained samples using light microscopy (Table 2).

\section{Immunohistochemistry}

Twelve of 13 samples received from the 1980s North Sea cases stained positive (red) using the polyclonal antibody of Francisella-specific IHC assay described above (Table 2). Positive staining was limited to areas where bacterial cells were present (Fig. 1A). The intensity of staining varied among individuals and stages of inflammatory processes; however, intensive positive staining was commonly observed in granulomatous tissue, where abundant bacteria were observed (Fig. 1B-H). Granulomas with central necrosis showed intensive positive staining mainly at the periphery (Fig. 1F,G); whereas granuloma without central necrosis showed positive staining centrally and/or scattered throughout (Fig. 1C,D). Bacteria were also observed in tissues without granuloma. The observed staining pattern was in accordance with that observed from recent $F$. noatunensis subsp. noatunensis infections in farmed Atlantic cod in Norway (Fig. 1H). No immunohistochemical evidence of mycobacterial involvement was identified.

\section{Real-time PCR, cloning and sequencing}

Of the 13 received FFPE tissue samples investigated, 6 were positive for Francisella noatunensis using the FopA assay (which detects both $F$. noatunensis and $F$. philomeragia, but not F. asiatica) and the Fc50 assay which detects both subspecies of $F$. noatunensis (Table 2). Obtained cycle threshold (Ct) values lay between 37 and 44 cycles and all were validated by cloning and sequencing of the Fc50 amplicon. The obtained sequences (101 bp) were identical and showed $100 \%$ identity with $F$. noatunensis subsp. noatunensis and $99 \%$ identity with $F$. noatunensis subsp. orientalis. Mycobacteria were not detected by PCR.

\section{DISCUSSION}

FFPE tissue samples from Atlantic cod exhibiting visceral granulomatosis/presumptive mycobacteriosis, collected from the southern North Sea during 1988, were examined for the presence of Francisella and/or mycobacterial infections using Francisella and Mycobacterium-specific IHC and real-time PCR assays. Use of real-time PCRs with different specificity for the closely related $F$. noatunensis subspecies and $F$. philomiragia, combined with PCR amplicon sequencing, allowed precise identification of $F$. noatunensis subsp. noatunensis within the examined tissues. Immunohistochemistry identified the close association between the presence of the bacterium and the observed pathological changes. Mycobacteria were not identified using traditional staining, IHC or real-time PCR.

While immunohistochemistry revealed the presence of many bacterial cells, the PCR Ct values obtained were quite high, indicating the presence of relatively 

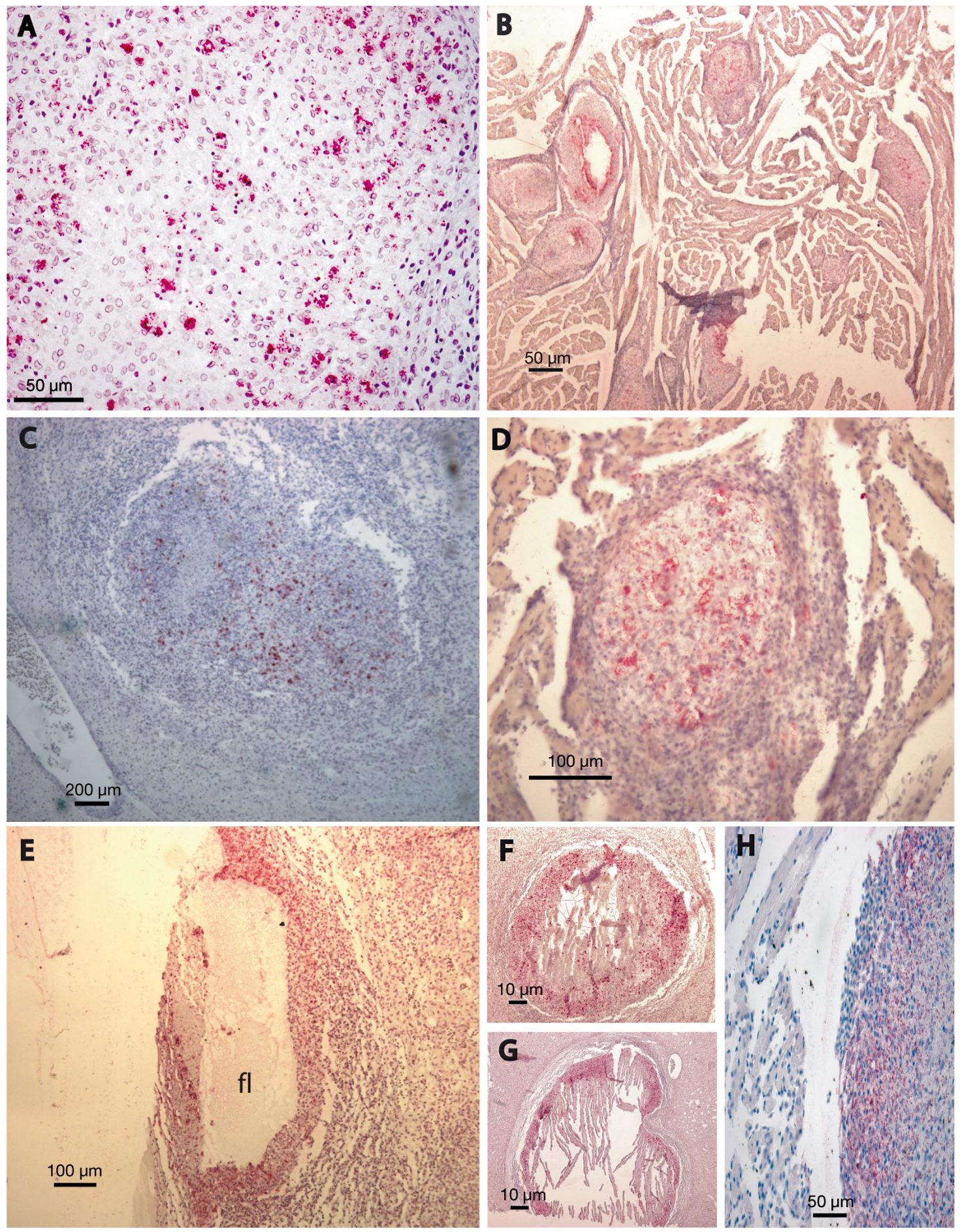

Fig. 1. Gadus morhua. Tissue sections of Atlantic cod (A-G) taken from the southern North Sea during the 1980s and (H) from Norwegian aquaculture in 2006, showing positive reaction (red) for the polyvalent anti-Francisella noatunensis rabbit serum. (A) Liver tissue showing an intensive staining of Francisella cells. (B) Heart tissue showing multiple granulomas with positively stained bacteria within these granulomas, central holes in some of the granulomas may represent cystic nodulation during Francisella infections. (C) Spleen tissue showing the presence of abundant positively stained bacteria in the centre of the granuloma. (D) Heart tissue showing presence of Francisella scattered within the granuloma. (E) Cystic granuloma of spleen tissue with a cavity in the centre and positively stained bacteria surrounding the cavity, showing fluid remains (fl). (F,G) Granuloma in spleen tissue with visible central necrosis and positively stained bacteria surrounding the necrotic tissue. (H) Heart tissue taken from clinical cases of $F$. noatunensis infection in Norwegian farmed Atlantic cod in 2006 
Table 2. Summary of test results conducted on 13 formalin-fixed paraffin-embedded (FFPE) Atlantic cod tissue samples taken from the southern North Sea during the 1980s. Histological examination used haematoxylin \& eosin stain for lesions and Ziehl-Neelsen-stain for acid-fast bacilli. Results for real-time PCR show cycle threshold (Ct) values rounded to whole numbers. Displayed Ct values were considered positive following cloning and sequencing of Fc50 PCR products

\begin{tabular}{|c|c|c|c|c|c|c|c|c|}
\hline \multirow{2}{*}{$\begin{array}{l}\text { Serial } \\
\text { no. }\end{array}$} & \multirow{2}{*}{$\begin{array}{l}\text { Fish } \\
\text { ID }\end{array}$} & \multirow[t]{2}{*}{ Organ } & \multicolumn{2}{|c|}{ Histology } & \multicolumn{2}{|c|}{ Real-time PCR } & \multicolumn{2}{|c|}{ Immunohistochemistry } \\
\hline & & & Lesion & $\begin{array}{l}\text { Acid-fast } \\
\text { bacilli }\end{array}$ & FopA & Fc50 & $\begin{array}{c}\text { Anti- } F \text {. } \\
\text { noatunensis }\end{array}$ & $\begin{array}{c}\text { Anti-Mycobacterium } \\
\text { spp. }\end{array}$ \\
\hline 1 & $147-1$ & Liver & Granuloma & - & $44(+)$ & $41(+)$ & + & - \\
\hline 2 & $147-2$ & Liver & Granuloma & - & $37(+)$ & $39(+)$ & + & - \\
\hline 3 & $147-3$ & Heart & Granuloma & - & $0(-)$ & $0(-)$ & + & - \\
\hline 4 & $147-4$ & Heart & Granuloma & - & $0(-)$ & $0(-)$ & - & - \\
\hline 5 & $148-\mathrm{A}$ & Liver & Granuloma & - & $41(+)$ & $38(+)$ & + & - \\
\hline 6 & 148-B & Heart & Granuloma & - & $0(-)$ & $0(-)$ & + & - \\
\hline 7 & $152-\mathrm{A}$ & Spleen & Granuloma & - & $41(+)$ & $44(+)$ & + & - \\
\hline 8 & $157-1$ & Spleen & Granuloma & - & $39(+)$ & $41(+)$ & + & - \\
\hline 9 & $157-2$ & Spleen & Granuloma & - & $0(-)$ & $0(-)$ & + & - \\
\hline 10 & $158-1$ & Spleen & Granuloma & - & $0(-)$ & $0(-)$ & + & - \\
\hline 11 & $158-2$ & Heart & Granuloma & - & $0(-)$ & $0(-)$ & + & - \\
\hline 12 & $159-1$ & Liver & Granuloma & - & $41(+)$ & $38(+)$ & + & - \\
\hline 13 & $159-3$ & Liver & Granuloma & - & $0(-)$ & $0(-)$ & + & - \\
\hline
\end{tabular}

small amounts of intact bacterial DNA. This may be explained by the relatively small amounts of tissue tested in each PCR reaction, the age of the paraffin blocks and the generally low amounts of DNA which can be effectively extracted from FFPE tissues, especially where the initial fixation may have been prolonged (Hewitt et al. 2008). To remove any doubts related to the validity of such high Ct values, subsequent cloning and sequencing of the PCR product identified unequivocally the presence of Francisella noatunensis subsp. noatunensis within the tissues. As francisellosis was unknown at the time of the original investigations, attempts at culture almost certainly failed due to the use of inappropriate media. Interestingly, visceral granulomatosis/presumptive mycobacteriosis was only observed in Atlantic cod and never identified north of latitude $55^{\circ} \mathrm{N}$ and inshore cod appeared to be more affected than offshore cod (Van Banning 1987, Bucke 1989, MAFF 1991). Not all granulomatous disease in cod can be attributed to francisellosis. While fish displaying similar pathological changes have been recorded sporadically at low prevalence, in the southern North Sea over the past 2 decades during fish disease monitoring and by anglers from the east coast of England (Cefas 2003), these have not been subjected to specific diagnostic investigation. Acid-fast bacilli were observed but not cultured from Atlantic cod displaying similar pathological lesions in Danish coastal waters (Dalsgaard et al. 1992)

Francisellosis has in recent years been fairly extensively identified in wild cod around the southern Norwegian coastline. Ottem et al. (2009) confirmed the presence of Francisella noatunensis in wild cod in sev- eral areas, both with and without active cod farming, at a prevalence of 7 to $22 \%$. Few fish however, displayed clinical signs of francisellosis. As this survey was performed after initial diagnosis of francisellosis in farmed cod, the prevalence in wild fish in Norway prior to the current widespread disease situation, with associated concurrent high infection pressure towards wild fish, is unknown.

Francisellosis has also been reported in wild cod off the west coast of Sweden at a prevalence of approximately $20 \%$ of caught fish (Alfjorden et al. 2006). While mature and market-sized fish were affected in cases from the southern North Sea, year class 1 fish were reported to be affected during the survey from the Swedish west coast.

Visceral granulomatosis was initially reported in wild cod from the southern North Sea. Whether the recent incidences of francisellosis in wild cod in Norway and Sweden are related to northerly spread of disease or whether they have been present, unidentified, for some time remains to be established (Olsen et al. 2006, Alfjorden et al. 2006, Ottem et al. 2008). The presence of francisellosis infection in wild cod suggests that wild fish are the probable source of infection in aquaculture stocks. Whether the higher infection pressure in the current cod farming systems might pose a threat to the wild population remains unknown.

In conclusion, the present study associates Francisella noatunensis subsp. noatunensis with visceral granulomatosis/presumptive mycobacteriosis in Atlantic cod sampled in the southern North Sea during the 1980s and further indicates that wild cod are the probable source of infection for francisellosis in Norwegian cod aquaculture. 
Acknowledgements. The authors are grateful to Dr. O. B. Dale for his contribution during the establishment of the immunohistochemistry assay. This study was partly supported by the Norwegian Research Council, project no. 1588823. The support of the Department for Environment, Food and Rural Affairs under contracts SLA24 and FB001 (to S.W.F.) is gratefully acknowledged.

\section{LITERATURE CITED}

Alfjorden A, Jansson E, Johansson KE (2006) A systemic granulomatous inflammatory disease in wild Atlantic cod, Gadus morhua, associated with a bacterium of the genus Francisella. DipNet Eur Network Newsl 44. www.dipnet. info/newsletters

Altschul SF, Madden TL, Schaffer AA, Zhang J, Zhang Z, Miller W, Lipman DJ (1997) Gapped BLAST and PSIBLAST: a new generation of protein database search programs. Nucleic Acids Res 25:3389-3402

Birkbeck TH, Feist SW, Verner-Jeffreys DW (2011) Francisella infections in fish and shellfish. J Fish Dis 34:173-187

Bucke D (1989) Observations on visceral granulomatosis and dermal necrosis in populations of North Sea cod. ICES CM 1989/E:17

Cefas (Centre for Environment, Fisheries \& Aquaculture Science) (2003) Monitoring of the quality of the marine environment, 1999-2000. Sci Ser Aquat Environ Monit Rep 54. Cefas, Lowestoft

Dalsgaard I, Mellergaard S, Larsen JL (1992) Mycobacteriosis in cod (Gadus morhua L.) in Danish coastal waters. Aquaculture 107:211-219

Hewitt SM, Lewis FA, Cao Y, Conrad RC and others (2008) Tissue handling and specimen preparation in surgical pathology: issues concerning the recovery of nucleic acids from formalin-fixed, paraffin-embedded tissue. Arch Pathol Lab Med 132:1929-1935

MAFF (Ministry of Agriculture, Fisheries and Food) (1991) Monitoring and surveillance of non-radioactive contami-

Editorial responsibility: David Bruno, Aberdeen, UK nants in the aquatic environment and activities regulating the disposal of wastes at sea, 1988-89. Aquat Environ Monit Rep 26. MAFF Direct Fish Res, Lowestoft

> Mikalsen J, Olsen AB, Tengs T, Colquhoun DJ (2007) Francisella philomiragia subsp. noatunensis subsp. nov., isolated from farmed Atlantic cod (Gadus morhua L.). Int J Syst Evol Microbiol 57:1960-1965

- Olsen AB, Mikalsen J, Rode M, Alfjorden A and others (2006) A novel systemic granulomatous inflammatory disease in farmed Atlantic cod, Gadus morhua L., associated with a bacterium belonging to the genus Francisella. J Fish Dis 29:307-311

> Ottem KF, Nylund A, Karlsbakk E, Friis-Møller A, Krossøy B, Knappskog D (2007) New species in the genus Francisella (Gammaproteobacteria; Francisellaceae); Francisella piscicida sp. nov. isolated from cod (Gadus morhua). Arch Microbiol 188:547-550

Ottem KF, Nylund A, Isaksen TE, Karlsbakk E, Bergh O (2008) Occurrence of Francisella piscicida in farmed and wild Atlantic cod, Gadus morhua L., in Norway. J Fish Dis 31:525-534

> Ottem KF, Nylund A, Karlsbakk E, Friis-Møller A, Kamaishi T (2009) Elevation of Francisella philomiragia subsp. noatunensis Mikalsen et al. (2007) to Francisella noatunensis comb. nov. [syn. Francisella piscicida Ottem et al. (2008) syn. nov.] and characterization of Francisella noatunensis subsp. orientalis subsp. nov., two important fish pathogens. J Appl Microbiol 106:1231-1243

> Thoresen OF, Falk K, Evensen O (1994) Comparison of immunohistochemistry, acid-fast staining, and cultivation for detection of Mycobacterium paratuberculosis in goats. J Vet Diagn Invest 6:195-199

Van Banning P (1987) Long-term recording of some fish diseases using general fishery research surveys in the southeast part of the North Sea. Dis Aquat Org 3:1-11

Zerihun MA, Hjortaas MJ, Falk K, Colquhoun DJ (2011) Immunohistochemical and Taqman real-time PCR detection of mycobacterial infections in fish. J Fish Dis 34: 235-246

Submitted: October 14, 2010; Accepted: January 31, 2011 Proofs received from author(s): May 12, 2010 